Check for updates

Cite this: Mater. Adv., 2020, 1, 1971

Received 1st July 2020, Accepted 28th July 2020

DOI: $10.1039 / \mathrm{d} 0 \mathrm{ma00467g}$

rsc.li/materials-advances

\title{
High intrinsic activity of the oxygen evolution reaction in low-cost $\mathrm{NiO}$ nanowall electrocatalysts $\dagger$
}

\author{
Salvatore Cosentino, (D) $\ddagger^{*^{a}}$ Mario Urso, (D) $\ddagger^{* a b}$ Giacomo Torrisi, ${ }^{\mathrm{b}}$ Sergio Battiato, \\ Francesco Priolo, ${ }^{\text {b }}$ Antonio Terrasi ${ }^{\mathrm{b}}$ and Salvo Mirabella ${ }^{\mathrm{ab}}$
}

\begin{abstract}
Earth-abundant materials for electrochemical water splitting typically show a lower efficiency than noble and rare metal electrocatalysts. Nanostructuring and appropriate material design can largely improve the performances of low-cost electrocatalysts, opening the route towards profitable mass production. Here, we report on a quantitative investigation of the oxygen evolution reaction (OER) on Ni-based nanowall (NW) electrodes. The $\mathrm{NiO}$ and $\mathrm{Ni}(\mathrm{OH})_{2} \mathrm{NW}$ films (200 or $400 \mathrm{~nm}$ thick) are produced by chemical bath deposition followed by calcination at $350{ }^{\circ} \mathrm{C}$. The morphology and the chemical arrangement of the NW were studied, before and after the OER, by scanning electron microscopy, energy dispersive X-ray analysis and $\mathrm{X}$-ray photoelectron spectroscopy. The OER electrocatalytic activity was investigated by electrochemical measurements under alkaline conditions ( $1 \mathrm{M} \mathrm{KOH}$ ), demonstrating a stable overpotential of $345 \mathrm{mV}$ at $10 \mathrm{~mA} \mathrm{~cm}{ }^{-2}$, a Tafel slope of $48 \mathrm{mV} \mathrm{dec}^{-1}$ and an $\mathrm{O}_{2}$ turnover conversion frequency (TOF) of up to $0.18 \mathrm{~s}^{-1}$. The quantitative measurement of active electrocatalysts, through cross-correlation of the experimental data, shows nearly $100 \%$ material utilization in the $200 \mathrm{~nm} \mathrm{NiO}$ NW. In thicker $\mathrm{NiO}$ or $\mathrm{Ni}(\mathrm{OH})_{2} \mathrm{NW}$ films this fraction decreases below $60 \%$, probably due to the decrease in the electric potential along the nanostructure, as revealed by numerical simulation. These data and discussion support the use of low-cost $\mathrm{Ni}$-based nanostructures for high-efficiency and sustainable electrocatalysts.
\end{abstract}

\section{Introduction}

Electrochemical water splitting represents a pivotal technology to produce energy in a sustainable, clean and diffuse way. ${ }^{1-4}$ The process of water splitting typically proceeds through two half reactions occurring at two electrodes: the cathodic hydrogen evolution reaction (HER) and the anodic oxygen evolution reaction (OER), which in the case of alkaline media can be summarized as: $:^{1,2}$

$$
4 \mathrm{H}_{2} \mathrm{O}+4 \mathrm{e}^{-} \rightarrow 2 \mathrm{H}_{2}+4 \mathrm{OH}^{-} \text {and } 4 \mathrm{OH}^{-} \rightarrow \mathrm{O}_{2}+2 \mathrm{H}_{2} \mathrm{O}+4 \mathrm{e}^{-}
$$

The main intrinsic limitation of this technology is related to the poor efficiency of the OER process, associated with slow reaction kinetics and high values of overpotential required for the formation of $\mathrm{O}_{2}$ through several intermediate reactions. ${ }^{1,5,6}$ The

\footnotetext{
${ }^{a}$ IMM-CNR and Università di Catania, via S. Sofia 64, 95123, Catania, Italy. E-mail: salvo.cosentino@gmail.com

${ }^{b}$ Dipartimento di Fisica e Astronomia "Ettore Majorana", Università di Catania, via S. Sofia 64, 95123, Catania, Italy. E-mail: mario.urso@dfa.unict.it

$\dagger$ Electronic supplementary information (ESI) available. See DOI: 10.1039/ d0ma00467g

\$ These two authors contributed to this work equally.
}

low efficiency of the OER is potentially detrimental also for the HER process and the final $\mathrm{H}_{2}$ conversion, since the two halfreactions proceed together in a complete electrochemical water splitting device. To date, Ir- and Ru-oxides have been the best reference electrocatalysts known for the OER, while Pt-coated electrodes have been used to efficiently drive the HER. ${ }^{1,4,7}$ However, the cost and low abundance of these electrocatalysts pose questions regarding their large-scale usage and thus numerous efforts have been directed towards the development of effective catalysts by using nanostructured and Earth abundant materials. ${ }^{4}$ Among the plethora of materials and compounds recently proposed as low-cost OER electrocatalysts, ${ }^{7-10}$ transition metal oxides and oxy-hydroxide nanomaterials are unquestionably promising candidates in large-scale electrochemical water splitting. ${ }^{11-13}$ In particular, Ni-oxide nanomaterials are well-assessed Earth abundant materials for efficient OER, especially in combination with other metal dopants. ${ }^{4,5,11,14-16}$ NiO-based nanostructures have already shown very proficient catalytic actions in sensing, electrochromical smart windows, supercapacitors and energy applications. ${ }^{17-23}$ Such materials have great potential to work also as an efficient backboneplatform electrocatalyst for both the HER and the OER. Doping 
or alloying with $\mathrm{Fe}$, Co, and Mn shows a large improvement in the performance of the Ni electrocatalyst for the OER, probably due to the optimization of the $\mathrm{OH}^{-}$bonding within the active sites. ${ }^{11,14}$ On the other side, alloying Ni with $\mathrm{P}$ or Mo shows a beneficial effect also for the HER. ${ }^{24-27} \mathrm{Ni}$-based nanostructures are thus extremely appealing as a full water splitting cell can be realized with bi-functional heterogeneous electrocatalytic sites for the HER and the OER. ${ }^{16}$ It has been recently shown that $\mathrm{Ni}-\mathrm{Co}-\mathrm{Fe}$ sulphide nanosheets on $\mathrm{Ni}$ nanocones act as high performance electrocatalysts for total electrochemical water splitting at a potential of $1.54 \mathrm{~V}$ to give a current density of $10 \mathrm{~mA} \mathrm{~cm}{ }^{-2} \cdot{ }^{28}$ Similarly, $\mathrm{Fe}^{2+}$-doped layered double (Ni, Fe) hydroxides are used for overall water splitting showing an overpotential of $1.54 \mathrm{~V}$ to give a current density of $10 \mathrm{~mA} \mathrm{~cm}{ }^{-2} .^{29}$ In photoelectrochemical water splitting the superior performance of Ni nanostructures in comparison to that of Ni dense materials has largely been shown and attributed to a more effective charge transfer process. ${ }^{30,31}$

Actually, there is currently great efforts within the materials science community to find electrocatalysts with superior performance for water splitting, and the nanotechnology approach greatly supports the progress in this direction. ${ }^{4,5,16}$ Nonetheless, while many papers report encouraging enhancements of the catalytic action when $\mathrm{Ni}$ (oxide) nanostructures are mixed with other elements, a net discrimination of the doping effect over the nanostructure advantages and a fundamental understanding of both are sometimes missing. In addition, a high loading of material electrocatalysts, as typically occurs for Earth abundant elctrocatalysts, could be as expensive as for noblemetal electrocatalysts due to their lower intrinsic activity. ${ }^{4}$ This highlights that for a real large-scale usage of water splitting methods, a clear determination of the mass activity is needed. Moreover, a fair comparison among the literature data and the reproducible results is still quite a challenge. It was magisterially shown that just a few nanomolar levels of $\mathrm{Ni}$ and $\mathrm{Fe}$ impurities in the electrolyte solution, coming from contaminated chemicals or glassware, are able to give rise to an OER current of up to $1 \mathrm{~mA}$ at an overpotential of $400 \mathrm{mV} .^{32,33}$ Therefore, controlled and reproducible experiments with quantitative metrics, and hopefully a solid understanding of the underlying mechanism, are urgently needed when a new performant electrocatalyst is claimed. ${ }^{1}$ Besides the ability to drive the efficient synthesis of nanostructures and to obtain the best usage of material resources, it would be as desirable to reliably measure the quantitative utilization of the catalytic material, which could help in developing specific shape, size and alloying of elements and compounds for efficient OER.

Here we report on a detailed and quantitative investigation of the OER in low-cost synthesized Ni-oxide based nanowalls (NW) without any intentional doping. $\mathrm{Ni}(\mathrm{OH})_{2}$ and $\mathrm{NiO} \mathrm{NW}$ are carefully synthesized by chemical bath deposition and both show a highly textured surface leading to effective ion exchange with the electrolyte. Electrochemical measurements show improved stability and high OER conversion efficiency in the thin NiO NW, while significant unused materials are estimated for the thick NW films. Numerical modelling of the electrical potential distribution along the NW explains the more effective electrochemical activation of the shorter NW, which is further corroborated by quantitative XPS analysis. These data and relative discussion shed a new light on the basic mechanisms of the OER process in Ni-based nanostructures.

\section{Experimental}

Particular care was taken to avoid any potential Fe contamination sources during all the experimental processes. The $\mathrm{Ni}(\mathrm{OH})_{2}$ NW was grown on cleaned substrates by chemical bath deposition (CBD) using new and Fe-free Teflon beakers. The substrates consisted of thin films of $\mathrm{Au}(50 \mathrm{~nm})$ on $\mathrm{Ti}(25 \mathrm{~nm})$ grown on quartz substrates by sputtering deposition. Quartz substrates were chosen on purpose to avoid Fe contamination and were carefully cleaned with acetone, isopropanol and DI water and dried in $\mathrm{N}_{2}$ before deposition. The chemical solution for $\mathrm{CBD}$ was prepared by mixing $0.42 \mathrm{M} \mathrm{NiSO} \cdot 6 \mathrm{H}_{2} \mathrm{O}$ (Alfa Aesar, 98\%), $0.07 \mathrm{M} \mathrm{K}_{2} \mathrm{~S}_{2} \mathrm{O}_{8}$ (Alfa Aesar, 97\%) and $3.5 \mathrm{wt} \%$ ammonia (Merck, 30-33 wt\% $\mathrm{NH}_{3}$ in $\mathrm{H}_{2} \mathrm{O}$ ) in DI water. ${ }^{22}$ The solution was heated up to $50{ }^{\circ} \mathrm{C}$ and kept at this temperature using a bain-marie setup. The substrates were immersed in CBD solution for a period of time ranging from 3 to $20 \mathrm{~min}$, in order to achieve growth of $\mathrm{Ni}(\mathrm{OH})_{2} \mathrm{NW}$ films with different thicknesses. Then, the samples were rinsed with deionized water to wash the deposited film from the unwanted microparticulate and dried in $\mathrm{N}_{2}$. Some samples were further annealed at $350{ }^{\circ} \mathrm{C}$ for $60 \mathrm{~min}$ in $\mathrm{Ar}$ in order to achieve calcination of films and obtain the NiO NW, as confirmed by XRD. ${ }^{17}$ The film mass after each synthesis step was measured with a Kern ABT-100 5NM (sensitivity of $0.01 \mathrm{mg}$ ) quartz microbalance (QCM).

The surface morphology and the sample thickness were characterized by using a scanning electron microscope (Gemini field emission SEM Carl Zeiss SUPRA 25) combined with energy dispersive X-ray spectroscopy (EDX).

Electrochemical analyses were performed using a Versastat-4 potentiostat in a three-electrode setup with Pt wire as the cathode, a saturated calomel electrode (SCE) as the reference electrode, and an Ni-based NW film as the working electrode. All the measurements were performed at room temperature and atmospheric pressure, in a one-compartment electrochemical Teflon cell filled with $100 \mathrm{~mL}$ of $1 \mathrm{M} \mathrm{KOH}$ (measured $\mathrm{pH}=13.5$ ) as the supporting electrolyte.

The potential distribution along the NW was numerically simulated by using COMSOL Multiphysics software. ${ }^{34}$ To simulate the NW electrode, a $20 \mathrm{~nm}$ thick NiO nanosheet was designed, while a bulk Au substrate was conceived as the current collector for the electrode. The following room temperature conductivities were used: $10^{-4} \mathrm{~S} \mathrm{~cm}^{-1}$ for NiO, $0.2 \mathrm{~S} \mathrm{~cm}^{-1}$ for $1 \mathrm{M} \mathrm{KOH}$ and an electrical permittivity of 11.9 for $\mathrm{NiO}^{35,36}$ A steady-state model was used to evaluate the electric field distribution across the electrode at a constant applied voltage of $1.6 \mathrm{~V}$.

X-ray photoelectron spectroscopy (XPS) analysis was used to investigate the oxidation state evolution of the NW before and 
after the OER. XPS spectra were recorded using an $\mathrm{Al}$ K $\alpha$ photon source $(1486.7 \mathrm{eV})$ and a hemispherical electron analyzer VG Microtech CLAM4 equipped with a multi-channeltron detector (MCD). The kinetic energy of the photoelectrons emitted from the sample surface was collected with a $20 \mathrm{eV}$ pass energy, resulting in a line spectral resolution of about $1.2 \mathrm{eV}$. Au $4 \mathrm{f}_{7 / 2}$ was used as the calibration peak at $84.0 \mathrm{eV}$. The deconvolution and fitting of the peaks were carried out with fityk software. ${ }^{37}$

\section{Results and discussion}

The $\mathrm{Ni}(\mathrm{OH})_{2}$ and NiO NW were synthesized through a two-step process, as schematized in the top panel of Fig. 1. The first step involves $\mathrm{CBD}$ at $50{ }^{\circ} \mathrm{C}$ to ensure the growth of the $\mathrm{Ni}(\mathrm{OH})_{2} \mathrm{NW}$ on top of the $\mathrm{Au}(50 \mathrm{~nm}) / \mathrm{Ti}(25 \mathrm{~nm}) /$ quartz substrate. The second step consists of post-growth thermal annealing in $\mathrm{Ar}$ at $350{ }^{\circ} \mathrm{C}$ for $1 \mathrm{~h}$, which induces dehydration of $\mathrm{Ni}(\mathrm{OH})_{2}$ into $\mathrm{NiO}$. Fig. S1a (ESI $\dagger$ ) shows the SEM image of the pristine $\mathrm{Ni}(\mathrm{OH})_{2}$ NW film, which consists of a densely interconnected array of thin $(\sim 20-30 \mathrm{~nm})$ sheets mostly perpendicular to the substrate. ${ }^{18}$ The $\mathrm{Ni}(\mathrm{OH})_{2} \mathrm{NW}$ film has a very high surface area of $30-40 \mathrm{~m}^{2} \mathrm{~g}^{-1}$, as measured previously by BET gas adsorption measurements. ${ }^{17}$ By increasing the synthesis time, the NW film thickness increases from $200 \mathrm{~nm}$ for $3 \mathrm{~min}$, to $400 \mathrm{~nm}$ for 20 min growth time (Table S1 and Fig. S2, ESI $\dagger$ ). Notably, the morphology of the annealed NiO NW films does not appreciably change compared to the pristine $\mathrm{Ni}(\mathrm{OH})_{2} \mathrm{NW}$ (Fig. S1, ESI $\dagger$ ), neither after the OER as shown in Fig. 1(a). In addition, EDX analysis, as shown in Fig. 1(b) and (c), confirmed that the NW composition is solely constituted by $\mathrm{Ni}$ and $\mathrm{O}$. The EDX peaks of $\mathrm{Au}$ and $\mathrm{Ti}$ are ascribed to the underneath electrode substrate. Contamination of $\mathrm{K}$ from the electrolyte solution appears for samples after the electrochemical OER, while no traces of Fe were detected within the resolution of the EDX $(<0.1 \%)$ as shown in the inset of Fig. 1(d), both before and after the OER (Fig. S3, ESI $\dagger$ ) analysis.

In order to measure the performances of the $\mathrm{Ni}(\mathrm{OH})_{2}$ and NiO NW electrocatalysts toward the OER, we performed a series of electrochemical measurements. In particular, each NW electrode was electrochemically characterized using the following series of tests: (1) electrochemical impedance spectroscopy (EIS); (2) cyclic voltammetry (CV); (3) EIS, (4) Tafel analysis (chronopotentiometry, CP); (5) EIS; (6) chronoamperometry (10 min); (7) CV and (8) the CP stability test for $5 \mathrm{~h}$. The measured potential was converted to the overpotential, $\eta^{\prime}$, against the reversible hydrogen electrode (RHE) according to the relationship: $:^{38,39}$

$$
\eta^{\prime}=E_{\mathrm{RHE}}-1.23=E_{\mathrm{SCE}}+E_{\mathrm{SCE}}^{0}+\ln 10 \frac{R T}{F} \cdot \mathrm{pH}
$$

where $E_{\mathrm{RHE}}$ and $E_{\mathrm{SCE}}$ are the potentials of the working electrode with respect to the RHE and the SCE, respectively. $E^{0}$ is the
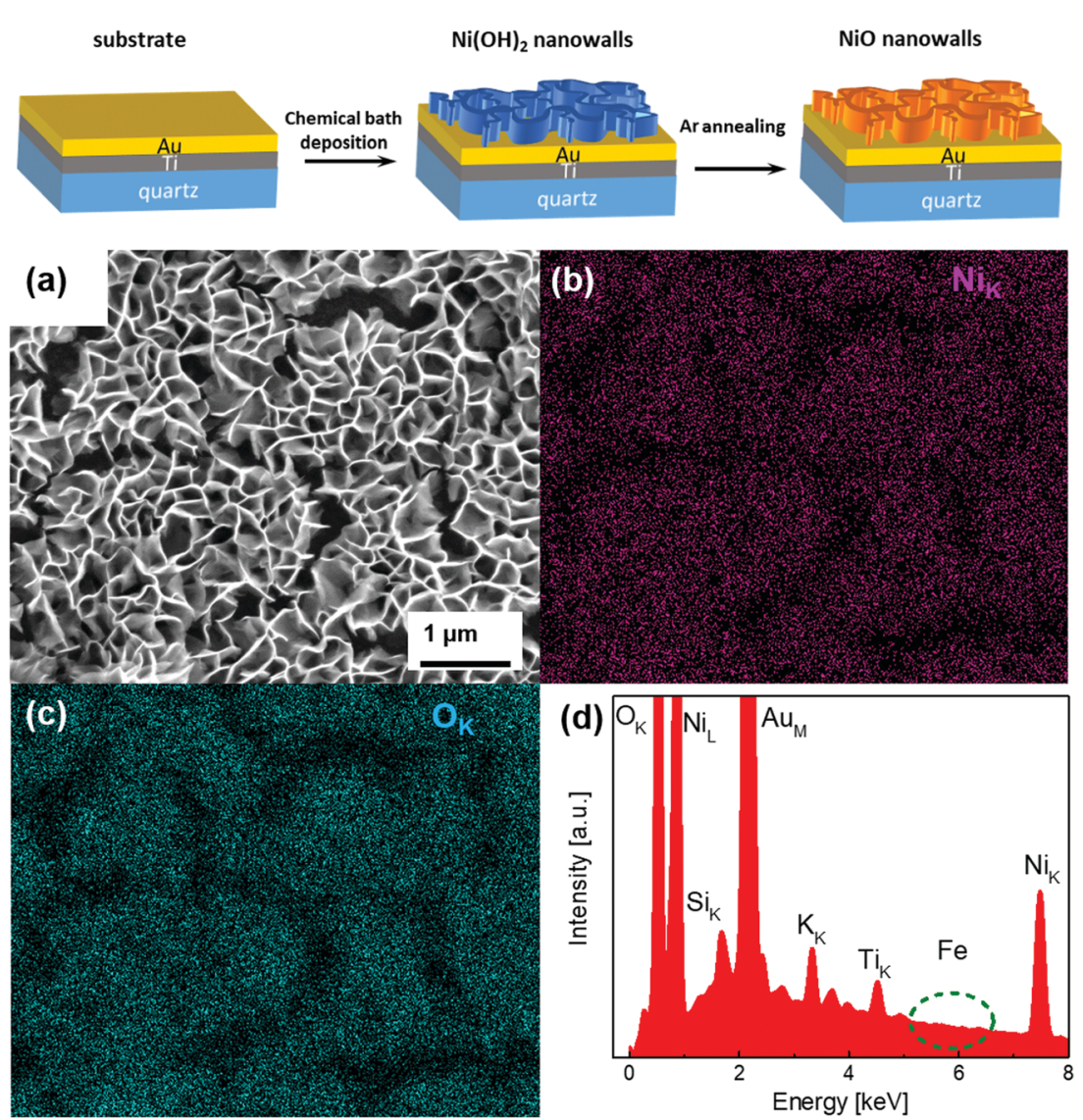

Fig. 1 SEM image of the NiO NW (a) and the corresponding EDX-SEM colour map for Ni (b) and O (c) atomic signals, together with the EDX survey (d). 


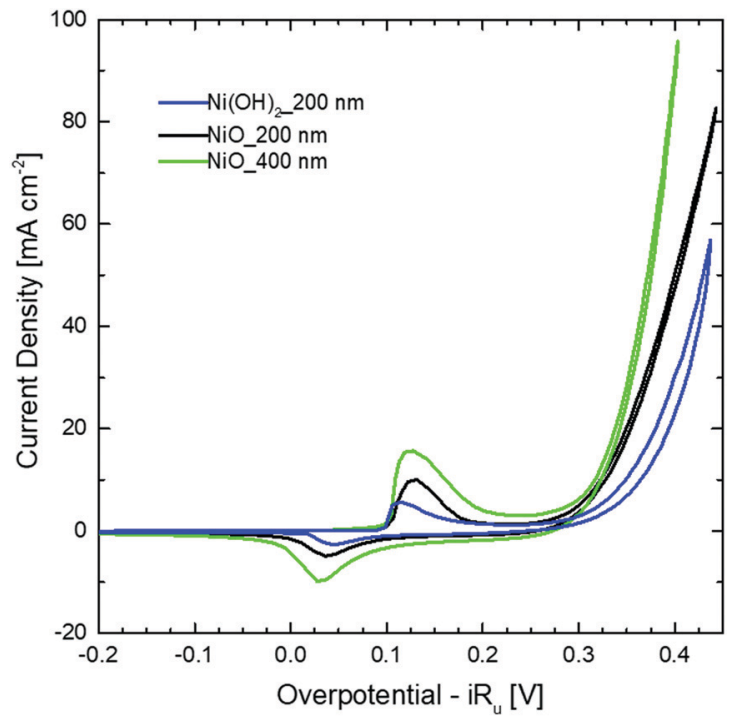

Fig. $2 \mathrm{CV}$ curves of $\mathrm{Ni}(\mathrm{OH})_{2}$ and $\mathrm{NiO}$ NW films deposited on $\mathrm{Au} / \mathrm{Ti} /$ quartz substrates. All curves refer to the 10th cycle and the overpotential was corrected for the uncompensated resistance estimated from the EIS measurements.

standard reduction potential of the reference electrode with respect to the RHE, while $R, T$, and $F$ are the gas constant, temperature, and Faraday constant. Moreover, the overpotential was also corrected for the uncompensated series resistance as follows:

$$
\eta=\eta^{\prime}-i R_{\mathrm{u}}
$$

where $i$ is the current collected at the electrode, while $R_{\mathrm{u}}$ [Ohms] is the intercept on the real axis of the Nyquist plots (real $v s$. imaginary part of the impedance, $Z$ ) obtained from the EIS measurements performed in a frequency range between $1 \mathrm{~Hz}$ and $100 \mathrm{kHz}$ at $0 \mathrm{~V} v s$. open circuit potential (see Fig. S4 in the ESI $\dagger)^{38}$

Fig. 2 shows the CV curves recorded for the $\mathrm{Ni}(\mathrm{OH})_{2} \mathrm{NW}$ and for two different thicknesses of the NiO NW electrocatalyst. Two pronounced oxidation and reduction peaks appear for all the samples, which are attributed to the redox couple $\mathrm{Ni}^{2+} / \mathrm{Ni}^{3+}$. At higher values of overpotential, a strong increase of the current appears, due to the OER occurring at the electrocatalyst surface. In this regard, the pristine $\mathrm{Ni}(\mathrm{OH})_{2} \mathrm{NW}$ electrode shows only moderate activity which is also accompanied by some electorcatalyst deterioration (Fig. S5, ESI $\dagger$ ). On the other side, the NiO NW electrocatalyst shows a higher current at a lower overpotential and increased stability. The latter is probably due to the increased stiffness of the NW film after calcination.

It is important to remember that both $\mathrm{NiO}$ and $\mathrm{Ni}(\mathrm{OH})_{2}$ follow a similar redox reaction, which can be simplified with a single-electron reaction as: ${ }^{40,41}$

$$
\begin{gathered}
\mathrm{Ni}(\mathrm{OH})_{2}+\mathrm{OH}^{-} \leftrightarrow \mathrm{NiOOH}+\mathrm{H}_{2} \mathrm{O}+\mathrm{e}^{-} \\
\mathrm{NiO}+\mathrm{OH}^{-} \leftrightarrow \mathrm{NiOOH}+\mathrm{e}^{-}
\end{gathered}
$$

Moreover, in Fe-free $\mathrm{Ni}$ oxides, $\mathrm{NiOOH}$ and especially its $\gamma$ phase are often described as potential active electrocatalysts for the OER. ${ }^{42,43}$ In particular, $\gamma-\mathrm{NiOOH}$ has a layered structure consisting of $\mathrm{NiOOH}$ planes and intercalated water molecules or ions, with a larger interplanar distance than $\beta$-NiOOH. ${ }^{44,45}$ This results in a higher Ni oxidation state in $\gamma-\mathrm{NiOOH}(3.5-3.67)$ than in $\beta-\mathrm{NiOOH}(3)$, and thus in a superior catalytic activity. ${ }^{42}$ Such a peculiar structural characteristic is morphologically accompanied by the high surfaces exposed by our NW film, which is optimal to involve a larger amount of atoms in the OER process than bulky electrocatalyst films. Moreover, several studies have recently reported that minimal impurities of $\mathrm{Fe}$ were sufficient to improve the catalytic activity of $\mathrm{Ni}(\mathrm{OH})_{2},{ }^{32,33}$ giving rise to an OER current of around $1 \mathrm{~mA}$ at $400 \mathrm{mV}$ of overpotential. Although SEM-EDX and XPS analyses did not show any signal due to significant iron contamination both before and after electrochemical measurements, still Fe traces below the detection limit $(<0.1 \%)$ cannot be completely excluded. However, we expect that the effect of such Fe contamination, if any, would be small and similar for all the investigated samples, keeping both the activity metrics and the latter discussion valid.

The stability of the NW electrodes was evaluated by running $\mathrm{CP}$ measurements with the electrodes kept at a current density of $10 \mathrm{~mA} \mathrm{~cm}{ }^{-2}$ for five hours, while the overpotential changes were recorded. Fig. S6 (ESI $\dagger$ ) shows a different behavior between the $\mathrm{NiO}$ and $\mathrm{Ni}(\mathrm{OH})_{2} \mathrm{NWs}$. The $\mathrm{Ni}(\mathrm{OH})_{2} \mathrm{NW}$ shows poor stability, with an overpotential stably increasing over time and exceeding the value of $420 \mathrm{mV}$ after $5 \mathrm{~h}$ of OER activity. In contrast, the NiO NW films show an improved electrochemical stability, with both the $200 \mathrm{~nm}$ and the $400 \mathrm{~nm}$ thick NWs evidencing a nearly constant overpotential of around $345 \mathrm{mV}$ and $350 \mathrm{mV}$, respectively. Similar to what was observed during the $\mathrm{CV}$ tests, such improved stability is probably related to a better stiffness of the NiO NW film compared to the bulk support electrode.

The different behavior observed in the $\mathrm{CV}$ and $\mathrm{CP}$ measurements between the $\mathrm{NiO}$ and $\mathrm{Ni}(\mathrm{OH})_{2} \mathrm{NW}$ films is related to the different activities of the electrocatalysts towards the OER. To compare the activity of various electrocatalysts in water splitting, the overpotential at a current density of $10 \mathrm{~mA} \mathrm{~cm}{ }^{-2}$ is often used. ${ }^{1,39}$ In this regard, as already clearly visible in Fig. 2 and 3 , one can generally conclude that the NiO NW performs better than the $\mathrm{Ni}(\mathrm{OH})_{2} \mathrm{NW}$ and the reaction becomes more effective when a thicker $\sim 400 \mathrm{~nm}$ NW electrocatalyst is used, since both the overpotential and stability are optimized. However, relying only on the values of the overpotential can be misleading since that is an intensive quantity and it is not quantitatively linked to the amount of active materials involved in the OER. For this reason, the steady-state Tafel equation was also used from the chronopotentiometry measurements to calculate the activity metrics. Generally, a smaller Tafel slope implies faster electrochemical kinetics. ${ }^{46,47}$ The Tafel slopes extrapolated from the linear fit of data points below $10 \mathrm{~mA} \mathrm{~cm}{ }^{-2}$ are shown in Fig. 3(a). The $\mathrm{Ni}(\mathrm{OH})_{2} \mathrm{NW}$ exhibits a slope of around $104 \mathrm{mV} \mathrm{dec}^{-1}$, while both the NiO NW electrodes exhibit a similar 

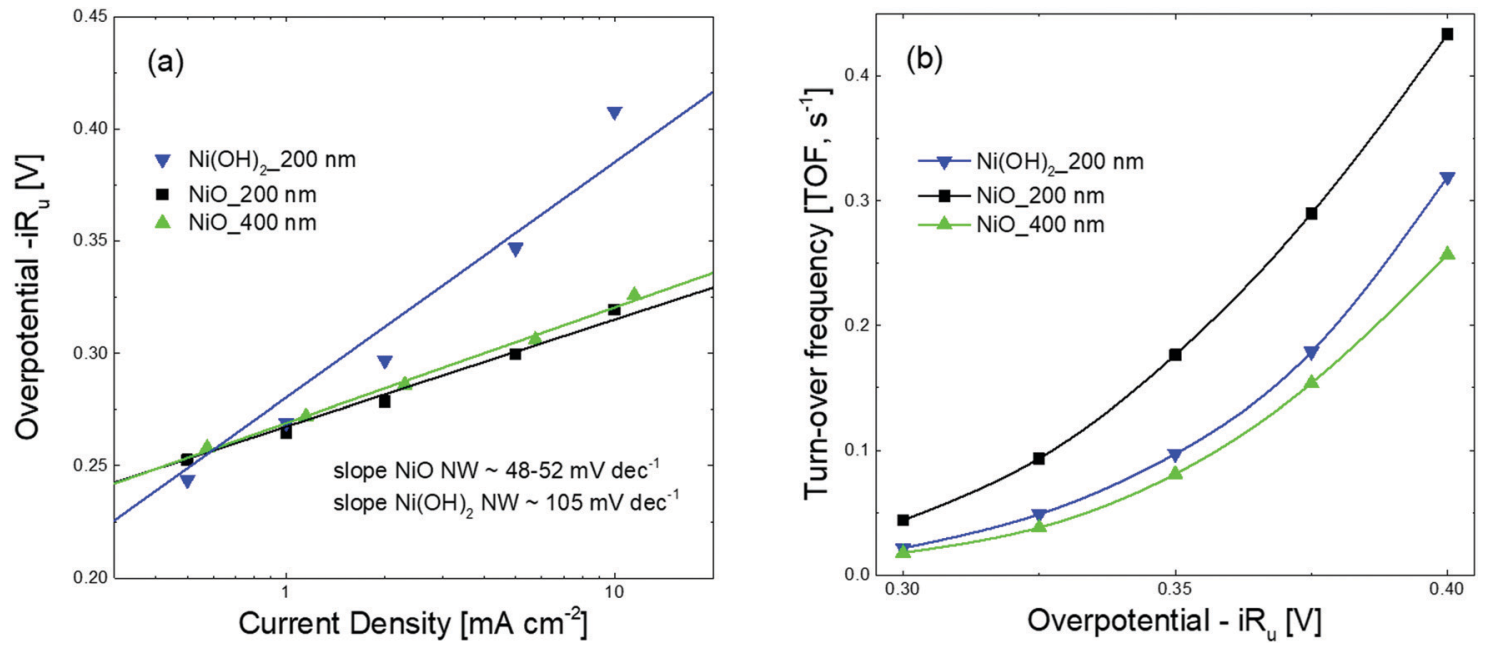

Fig. 3 Steady-state Tafel plots (a) and turn-over frequency (TOF) curves (b) of $\mathrm{Ni}(\mathrm{OH})_{2}$ and $\mathrm{NiO} \mathrm{NWs}$ films. The values of the overpotential for Tafel analysis were acquired from CP measurements in steps from $0.05 \mathrm{~mA} \mathrm{~cm}{ }^{-2}$ to $10 \mathrm{~mA} \mathrm{~cm}$, each held for 3 min. The TOF values were calculated considering the number of active sites extracted from electrochemical measurements (TOF redox), or measured by QCM (TOF ${ }_{Q C M}$ ).

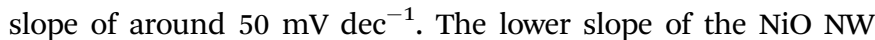
compared to that of the $\mathrm{Ni}(\mathrm{OH})_{2} \mathrm{NW}$ might be related to a different OER process pathway. In fact, the Tafel slope around $120 \mathrm{mV} \mathrm{dec}{ }^{-1}$ is typically observed when the reaction proceeds as $\mathrm{M}+\mathrm{OH}^{-} \rightarrow \mathrm{MOH}+\mathrm{e}^{-}$, where $\mathrm{M}$ denotes the active site on the surface. ${ }^{47}$ However, when the surface has already some adsorbed $\mathrm{OH}$ species the reaction is found to proceed at a lower Tafel slope, typically around $30-40 \mathrm{mV} \mathrm{dec}{ }^{-1} .^{47}$ In this regard, it was recently shown that the increased electrochemical kinetics of the $\mathrm{NiO}_{x}$ structures compared to that of $\mathrm{Ni}(\mathrm{OH})_{2}$ is related to an increased amount of oxygen vacancies and point defects, favouring the adsorption of hydroxide groups and driving the OER at a lower energy rate step. ${ }^{15,40,42}$ This would lead to a more favourable formation of $\mathrm{NiOOH}$ complexes at the electrocatalyst surface and to a more effective OER process. Moreover, the better stiffness of the NiO NW might help in improving the electrochemical stability of the entire film at a high current density.

To shed more light on the different activities between the $\mathrm{Ni}(\mathrm{OH})_{2}$ and NiO NW films, we also extracted more quantitative information on the amount of electrocatalysts participating in the OER by analysing the oxidation peak in the CV curves. As shown in Fig. 2, a clear difference among the investigated samples appears in the intensity of the redox peaks, which is intimately related to a different electro-catalytic activity. In fact, the area underneath the peak is proportional to the amount of active electrocatalytic sites available for the OER process. ${ }^{39,48}$
The current $i$ recorded during $\mathrm{CV}$ is a measure of the charge $Q$ passed over a period of time: $=\frac{\mathrm{d} Q}{\mathrm{~d} t}$. Given that the current sweep is acquired at a given scan rate, $=\frac{E}{t}$, the integration of the current peak returns the amount of charge passed through the electrode during the redox reaction. This relationship is valid with the assumption that the redox reaction is a oneelectron transfer process as written in reaction (1). In our case, the $\mathrm{Ni}(\mathrm{OH})_{2} \mathrm{NW}$ electrode exhibits the smallest area of the peak, corresponding to an amount of $1.7 \times 10^{17}$ active sites per $\mathrm{cm}^{2}$. Instead, the NiO NW has an amount of active sites increasing from $2.8 \times 10^{17}$ sites per $\mathrm{cm}^{2}(200 \mathrm{~nm})$ to $5.6 \times 10^{17}$ sites per $\mathrm{cm}^{2}$ $(400 \mathrm{~nm})$, as reported in Table 1 .

The number of active electrocatalytic sites determined from the electrochemical measurements is in good agreement with the total density of the electrocatalyst, as obtained from the QCM measurements and reported in Table S1 (ESI $\dagger$ ). In particular, for both the $200 \mathrm{~nm}$ samples, the number of active electrocatalysts closely matches with that obtained by QCM. This means that nearly all atoms participate in the OER process, confirming that the nanostructures are effective for material utilization. In fact, the porous-like 3D morphology of our NW thin films is of great help for optimizing the amount of electrocatalysts ionically connected to the $\mathrm{OH}^{-}$groups and electronically connected to the current collector. Nonetheless,

Table 1 Activity metrics of $\mathrm{Ni}(\mathrm{OH})_{2}$ and $\mathrm{NiO} \mathrm{NW}$ electrocatalysts

\begin{tabular}{llll}
\hline & $\mathrm{Ni}(\mathrm{OH})_{2 \_} 200 \mathrm{~nm}$ & NiO_200 $\mathrm{nm}$ & NiO_400 $\mathrm{nm}$ \\
\hline Overpotential at $10 \mathrm{~mA} \mathrm{~cm}^{-2}[\mathrm{mV}]$ & 420 & 345 & 350 \\
Tafel slope $\left[\mathrm{mV} \mathrm{dec}^{-1}\right]$ & 104 & 48 & 52 \\
Number of active $\operatorname{sites}\left[\times 10^{17} \mathrm{~cm}^{-2}\right]$ & 1.7 & 2.8 & 5.6 \\
Total active electrocatalyst $\left[\mu \mathrm{mol} \mathrm{cm}^{-2}\right]$ & 0.28 & $\sim 100 \%$ & 0.91 \\
Fraction of active electrocatalyst $[ \pm 10 \%]$ & $80 \%$ & $20.1 \times 10^{-3}$ & $57 \%$ \\
Current density at $\eta=350 \mathrm{mV}\left[\mathrm{A} \mathrm{cm}{ }^{-2}\right]$ & $7.05 \times 10^{-3}$ & $1.8 \times 10^{-1}$ & $28.5 \times 10^{-3}$ \\
TOF at $\eta=350 \mathrm{mV}\left[\mathrm{s}^{-1}\right]$ & $9.7 \times 10^{-2}$ &
\end{tabular}


it is worth noting that the thicker NiO NW has a lower fraction of active electrocatalysts, suggesting limited effectiveness of the OER process. To better investigate the metrics relevant to the intrinsic activity of the electrocatalysts in the OER, the turn-over frequency (TOF) must be considered. ${ }^{4}$ The TOF is defined as the rate of production of oxygen molecules per available (and active) site:

$$
\mathrm{TOF}=\frac{I}{4 n F}
$$

where $I$ is the measured current at a certain overpotential, $F$ is the Faraday constant (96485 $C \mathrm{~mol}^{-1}$ ) and $n$ is the number of moles of the available (active) sites determined by QCM $\left(\mathrm{TOF}_{\mathrm{QCM}}\right)$ or by the redox peak integration $\left(\mathrm{TOF}_{\text {redox }}\right)$. It should be noted that, unfortunately, the literature data are usually biased towards the record activity claiming and often discarding the amount of available sites and the activity of each catalytic site. ${ }^{4}$ The $\mathrm{TOF}_{\mathrm{QCM}}$ and $\mathrm{TOF}_{\text {redox }}$ are extremely useful metrics for determining the activity of each site, even if on an average scale, considering the full electrocatalyst loading or the redox active one, respectively. A higher TOF is desirable since each available site produces more $\mathrm{O}_{2}$ molecules per unit time, as well as a convergence between $\mathrm{TOF}_{\mathrm{QCM}}$ and $\mathrm{TOF}_{\text {redox }}$ is wished for better material utilization. Fig. 3(b) shows the trends of the $\mathrm{TOF}_{\mathrm{QCM}}$ and $\mathrm{TOF}_{\text {redox }}$ values in the $300-400 \mathrm{mV}$ overpotential range. Clearly, the TOF increases with the applied overpotential for kinetics reasons, and still the number of active sites really matters for defining the effectiveness of the OER process. The $200 \mathrm{~nm}$-thin NiO NW film always shows higher values of TOF and a nice convergence of $\mathrm{TOF}_{\mathrm{QCM}}$ and $\mathrm{TOF}_{\text {redox }}$ meaning that on average all the active sites are available to activate an effective OER. As reported in Table 2, a TOF of $0.18 \mathrm{~s}^{-1}$ is obtained at $350 \mathrm{mV}$ of overpotential. Although the $\mathrm{Ni}(\mathrm{OH})_{2} \mathrm{NW}$ film has a fraction of active electrocatalyst comparable to that of the $200 \mathrm{~nm}$-thin NiO NW film, its TOF values are systematically lower as demonstrated by its minor OER current. Increasing the thickness of the NiO NW film leads to an expected increase of the current density, but still the material utilization decreases as shown by the considerably reduced TOF. Such behavior reveals that increasing the thickness of the NW film does not always lead to a corresponding increase of the intrinsic OER performance, because of the lower percentage of the active electrocatalyst. In the thicker NW, the electrochemical properties are somehow weakened, leading to less effective material utilization. The highest mass activity has been found for the $200 \mathrm{~nm}$ thin $\mathrm{NiO}$ NW film with a remarkable value of $0.33 \mathrm{~A} \mathrm{mg}^{-1}$ at a current of $10 \mathrm{~mA} \mathrm{~cm}{ }^{-2}$ with an overpotential of $345 \mathrm{mV}$. The measured activity metrics of all our samples are considerably higher, or among the highest performances reported in the literature for NiO based electrocatalysts, as shown in Table 2. Indeed, our NiO NW electrocatalyst shows the best combination because of its low values of overpotential and Tafel slope and a high TOF.

In order to study the origin of the higher activity for the smaller NiO NW, the electric potential field distribution along the NW electrode during the electrochemical activity was simulated by using the COMSOL Multiphysics software. The simulation on such a macroscopic quantity can offer a valuable understanding of the basic processes occurring at the nanoscale. The results of the applied potential distribution across the NW are presented in Fig. 4 in a false colour scale from 1.3 to $1.6 \mathrm{~V}$. The $200 \mathrm{~nm}$-thin NW displays a nearly uniform potential field along its structure, with a minimal potential decrease, lower than $0.1 \mathrm{~V}$, near the top region of the NW. By doubling the NW length, a considerably larger potential decrease is observed, with a NW tip at a potential $0.3 \mathrm{~V}$ below the $\mathrm{Au}$ contact. This effect is detrimental for the OER since only a portion of the material is at a potential high enough to achieve the electrochemical reaction. This effect helps explain the reduced activity metrics evaluated for the thicker NW film electrodes. Only the region close to the NW-substrate interface experiences a potential high enough to efficiently drive the OER process. On the top region of the longer NW, the potential field is reduced to a level close to the thermodynamic limit for the OER of $1.23 \mathrm{eV}$, for which the reactions can only poorly occur.

Finally, to compare the OER activity of the NiO NW with the chemical evolution at the electrode surface, we performed XPS analysis on the $400 \mathrm{~nm}$-thick NiO NW film electrode before and after the OER. In particular, for the NiO NW electrode we ran a $\mathrm{CP}$ test at $10 \mathrm{~mA} \mathrm{~cm} \mathrm{~cm}^{-2}$ for $1 \mathrm{~h}$ just before introducing it into the XPS analysis chamber. This was done with the intention of verifying whether the lower TOF estimated thicker NW film is related to incomplete chemical transformation of the electrocatalyst and to the presence of an inert material.

Table 2 Activity metrics of $\mathrm{NiO}$ based electrocatalysts for the OER

\begin{tabular}{|c|c|c|c|c|c|c|}
\hline Electrocatalyst material & Electrolyte & $\begin{array}{l}\text { Overpotential }(\mathrm{mV}) \\
\text { at } 10 \mathrm{~mA} \mathrm{~cm}-\mathrm{cm}^{-2}\end{array}$ & $\begin{array}{l}\text { Tafel slope } \\
\left(\mathrm{mV} \mathrm{dec}^{-1}\right)\end{array}$ & $\begin{array}{l}\text { TOF }\left(\mathrm{s}^{-1}\right) \\
\text { at } \eta=350 \mathrm{mV}\end{array}$ & Electrode & Ref. \\
\hline NiO hollow nanofibers & $1 \mathrm{M} \mathrm{KOH}$ & 322 & 78 & 0.07 & $\mathrm{Ni}$ foam & 49 \\
\hline $\mathrm{NiO}$ nanowalls & $1 \mathrm{M} \mathrm{KOH}$ & 310 & 54 & NA & Nickel foam & 52 \\
\hline $\mathrm{NiO}$ thin films & $0.5 \mathrm{M} \mathrm{KOH}$ & 360 & 30 & 0.07 & ITO & 53 \\
\hline $\mathrm{Ni}(\mathrm{OH})_{2}$ nanoplates & $0.1 \mathrm{M} \mathrm{KOH}$ & 474 & 87 & $0.015($ at $490 \mathrm{mV})$ & ITO & 54 \\
\hline $\mathrm{NiO}$ nanosheets & $0.1 \mathrm{M} \mathrm{KOH}$ & 422 & 116 & NA & Carbon cloth & 57 \\
\hline NiO nanosheets & $1 \mathrm{M} \mathrm{KOH}$ & 320 & 52 & NA & Graphene & 58 \\
\hline NiO nanowalls & $1 \mathrm{M} \mathrm{КОН}$ & 345 & 48 & 0.18 & Quartz/Ti/Au & This work \\
\hline
\end{tabular}




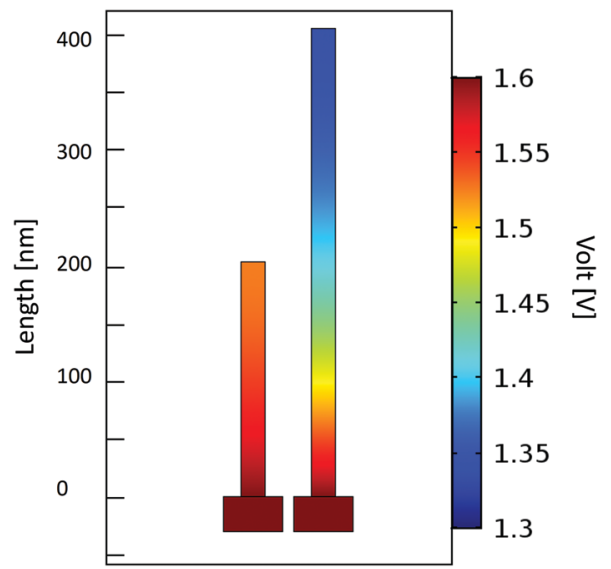

Fig. 4 Electric potential distribution in the $\mathrm{NiO} N W$ electrodes with different NW sizes in $1 \mathrm{M} \mathrm{KOH}$ solution for $1.6 \mathrm{~V}$ of applied bias, as simulated by the COMSOL Multiphysics software. A $20 \mathrm{~nm}$ thick and 200 (or) $400 \mathrm{~nm}$ tall $\mathrm{NiO}$ nanosheet was used to simulate the NiO NW electrodes.

Fig. 5 shows the Ni $2 p_{3 / 2}$ and $\mathrm{O} 1 \mathrm{~s}$ spectra of the NiO NW before and after the OER. The quantification and interpretation of the XPS peak shape of the Ni-based oxides are not trivial, due to the presence of extended multiplets, shake-up and plasmon loss structures, which can be confused with the overlapping of different chemical states of $\mathrm{Ni}^{59-61}$ For the XPS data fitting, the extensive study done by Biesinger $e t$ al. was used as a guideline. ${ }^{60}$ They concluded that the full $\mathrm{Ni} 2 \mathrm{p}$ photoemission envelope for pure $\mathrm{Ni}^{2+}$ species (e.g., $\mathrm{NiO}$ or $\mathrm{Ni}(\mathrm{OH})_{2}$ ) and pure $\mathrm{Ni}^{3+}$ species (e.g., $\gamma$-NiOOH) can be fit with a unique set of seven components. ${ }^{60,61}$ The binding energies, peak distances and FWHM were kept fixed in our fitting, according to the values given by Biesinger et al. ${ }^{60}$ while only the peak intensities were used as free parameters. The fit values are summarized in Table S2 of the ESI. $\dagger$

Fig. 5(a) shows the Ni $2 \mathrm{p}_{3 / 2}$ spectra of the NiO NW before the OER (as annealed). The broad peak in the range between 852 and $858 \mathrm{eV}$ is due to the overlap of the NiO component (the main peak at $853.6 \mathrm{eV}$ and the multiplet at $855.2 \mathrm{eV}$ ) with the $\mathrm{Ni}(\mathrm{OH})_{2}$ multiplet peaks, while the broad shoulder between 858 and $868 \mathrm{eV}$ is due to the satellite peaks of $\mathrm{NiO}$ and $\mathrm{Ni}(\mathrm{OH})_{2}$. The presence of peaks related to the $\mathrm{Ni}(\mathrm{OH})_{2}$ states in the $\mathrm{NiO}$ films is not unexpected, since hydroxide groups can readily adsorb on the surface because of ambient moisture. ${ }^{58}$ Interestingly, the same information also comes from the $\mathrm{O}$ 1s peak shown in Fig. 5(b), where the peak at $529.6 \mathrm{eV}$ is related to the Ni-O bond and is accompanied by a peak at 531.1 due to $\mathrm{Ni}(\mathrm{OH})_{2}$, together with an adventitious contamination peak at $532 \mathrm{eV}$ and water adsorbates at around $533.3 \mathrm{eV}$. From both the Ni $2 \mathrm{p}$ and $\mathrm{O} 1 \mathrm{~s}$ spectra, the ratio of the intensities of the components related to the $\mathrm{Ni}(\mathrm{OH})_{2}$ and $\mathrm{NiO}$ peaks (see Table $\mathrm{S} 2$ in the ESI $\dagger$ ) indicates that about $40 \%$ of the Ni atoms in the NiO NW film before the OER is actually in the chemical state of $\mathrm{Ni}(\mathrm{OH})_{2}$. Therefore, it is
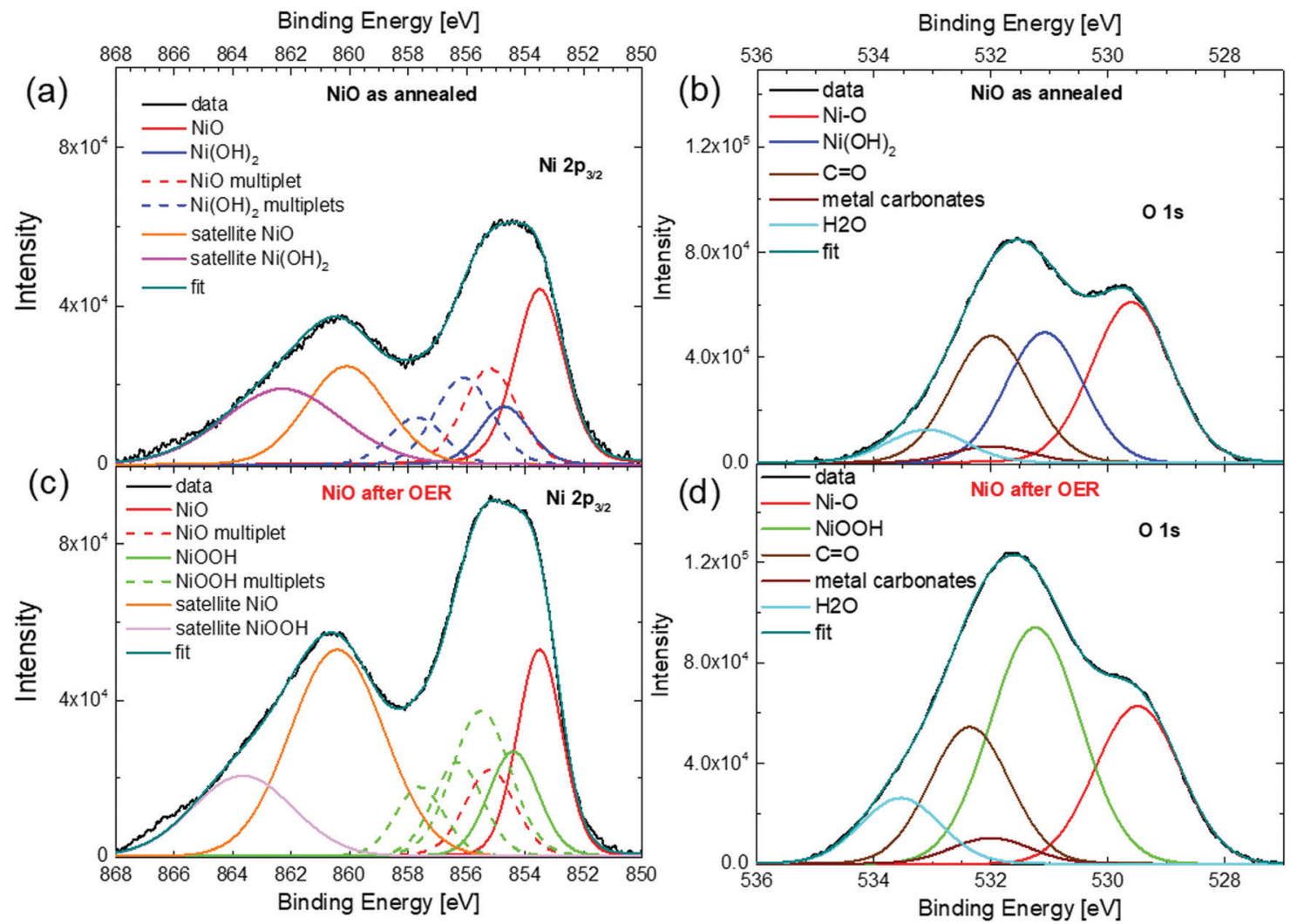

Fig. 5 XPS spectra of the $400 \mathrm{~nm}$ thick NiO NW electrocatalyst. Ni 2p p/2 (a) and O 1s (b) for the NiO NW before the OER. Ni $2 p_{3 / 2}$ (c) and O $1 \mathrm{~s}$ (d) for the $\mathrm{NiO}$ NW after the OER. 
reasonable to assume that the freshly annealed $\mathrm{NiO} \mathrm{NW}$ has a thin shell of $\mathrm{Ni}(\mathrm{OH})_{2}$ of a few nm surrounding the NiO core. The presence of such a bimodal chemical composition of $\mathrm{Ni}$ atoms is maintained also in the Ni 2p and O 1s XPS spectra of the NW electrode after the OER, as shown in Fig. 5(c) and (d). The presence of $\mathrm{NiO}$ is confirmed by the peak at $853.5 \mathrm{eV}$ for $\mathrm{Ni}$ $2 \mathrm{p}_{3 / 2}$ and at $529.5 \mathrm{eV}$ for the $\mathrm{O} 1 \mathrm{~s}$ spectra. However, as especially evident from the $\mathrm{O} 1 \mathrm{~s}$ spectrum, a larger signal comes from the $\mathrm{Ni}^{3+}$ species due to the presence of $\mathrm{NiOOH}$. From the quantitative analysis of the intensities of the peaks related to $\mathrm{NiO}$ and $\mathrm{NiOOH}$, it is possible to estimate that $\mathrm{NiOOH}$ constitutes only about $60 \%$ of the overall composition of the NW electrode after the OER. Such a value is further confirmation that around $40 \%$ of the total amount of atoms, an amount that is not negligible, does not follow the redox reaction and is not active towards the OER in the thick NW film. Such an amount of inert atoms is perfectly in agreement with the estimation of the inactive electrocatalyst in the electrochemical activity metrics and in conceptual agreement with the large potential decrease calculated for the $400 \mathrm{~nm}$-thick NW film.

Thus, for the design of novel Ni-based electrocatalysts, one should focus on optimizing the thickness of the electrocatalysts and increasing the amount of available electrocatalytic sites by increasing the total surface area, instead of indefinitely increasing the thickness and the mass loading only.

\section{Conclusions}

We performed a quantitative investigation of the OER process in highly textured $\mathrm{Ni}(\mathrm{OH})_{2}$ and NiO NW films, synthesized by lowcost methods. Electrochemical measurements revealed that, in comparison to $\mathrm{Ni}(\mathrm{OH})_{2}$, the $\mathrm{NiO} \mathrm{NW}$ film shows a significant improvement in the OER performance, with an overpotential of $345 \mathrm{mV}$ and a Tafel slope as low as $48 \mathrm{mV} \mathrm{dec}^{-1}$. The noteworthy performances of the NiO NW are also supported by its high activity metrics, in terms of a mass activity up to $0.33 \mathrm{~A} \mathrm{mg}^{-1}$ and a TOF value of $0.18 \mathrm{~s}^{-1}$ at $350 \mathrm{mV}$ overpotential. By comparing the NiO NW at different lengths, electrochemical measurements showed that a lower percentage of active sites is found, bringing down the overall OER performance. Nearly all the available sites are active in a $200 \mathrm{~nm}$ long NW, while in a longer $400 \mathrm{~nm}$ NW less than $60 \%$ of the electrocatalyst is involved in the OER. A numerical simulation of the electrical potential distribution and a detailed XPS analysis confirm that a large part of $\mathrm{NiO}$ in the longer NW films remains in an inert chemical state, probably because a lower electric potential is experienced. Such results contribute towards building a solid understanding of the OER mechanism in Ni-based nanostructures, and can help in defining a roadmap for material optimization in nanostructured electrocatalysts.

\section{Conflicts of interest}

All authors contributed to the final version of this paper. The authors declare that there is no conflict of interest regarding the publication of this article.

\section{Acknowledgements}

Sergio Battiato aknowledges the project AIM1804097 - Programma Operativo Nazionale FSE -FESR "Ricerca e Innovazione 20142020", Mario Urso aknowledges the project PON MIUR ADAS+ (ARS01_00459).

\section{References}

1 I. Roger, M. A. Shipman and M. D. Symes, Nat. Rev. Chem., 2017, 1(1), 1-13.

2 J. Rongé, T. Bosserez, D. Martel, C. Nervi, L. Boarino, F. Taulelle, G. Decher, S. Bordiga and J. A. Martens, Chem. Soc. Rev., 2014, 43, 7963-7981.

3 A. Landman, H. Dotan, G. E. Shter, M. Wullenkord, A. Houaijia, A. Maljusch, G. S. Grader and A. Rothschild, Nat. Mater., 2017, 16(6), 646-651.

4 J. Kibsgaard and I. Chorkendorff, Nat. Energy, 2019, 4(6), 430-433. 5 J.-W. Wang, W.-J. Liu, D.-C. Zhong and T.-B. Lu, Coord. Chem. Rev., 2019, 378, 237-261.

6 T. Hisatomi, K. Takanabe and K. Domen, Catal. Lett., 2015, 145(1), 95-108.

7 S. Chen, S. S. Thind and A. Chen, Electrochem. Commun., 2016, 63, 10-17.

8 X. Li, X. Hao, A. Abudula and G. Guan, J. Mater. Chem. A, 2016, 4(31), 11973-12000.

9 A. Shinde, D. Guevarra, J. A. Haber, J. Jin and J. M. Gregoire, J. Mater. Res., 2015, 30(3), 442-450.

10 X. Zou and Y. Zhang, Chem. Soc. Rev., 2015, 44(15), 5148-5180.

11 M. S. Burke, L. J. Enman, A. S. Batchellor, S. Zou and S. W. Boettcher, Chem. Mater., 2015, 27(22), 7549-7558.

12 J. B. Gerken, S. E. Shaner, R. C. Massé, N. J. Porubsky and S. S. Stahl, Energy Environ. Sci., 2014, 7(7), 2376-2382.

13 B. Zhang, X. Zheng, O. Voznyy, R. Comin, M. Bajdich, M. García-Melchor, L. Han, J. Xu, M. Liu, L. Zheng, F. P. G. de Arquer, C. T. Dinh, F. Fan, M. Yuan, E. Yassitepe, N. Chen, T. Regier, P. Liu, Y. Li, P. De Luna, A. Janmohamed, H. L. Xin, H. Yang, A. Vojvodic and E. H. Sargent, Science, 2016, 352(6238), 333-337.

14 D. Friebel, M. W. Louie, M. Bajdich, K. E. Sanwald, Y. Cai, A. M. Wise, M.-J. Cheng, D. Sokaras, T.-C. Weng, R. AlonsoMori, R. C. Davis, J. R. Bargar, J. K. Nørskov, A. Nilsson and A. T. Bell, J. Am. Chem. Soc., 2015, 137(3), 1305-1313.

15 Q. Hu, X. Huang, Z. Wang, G. Li, Z. Han, H. Yang, X. Ren, Q. Zhang, J. Liu and C. He, J. Mater. Chem. A, 2020, 8(4), 2140-2146.

16 Y. Li, X. Bao, D. Chen, Z. Wang, N. Dewangan, M. Li, Z. Xu, J. Wang, S. Kawi and Q. Zhong, ChemCatChem, 2019, 11(24), 5913-5928.

17 K. O. Iwu, A. Lombardo, R. Sanz, S. Scirè and S. Mirabella, Sens. Actuators, B, 2016, 224, 764-771.

18 M. Urso, G. Pellegrino, V. Strano, E. Bruno, F. Priolo and S. Mirabella, Nanotechnology, 2018, 29(16), 165601.

19 M. Urso, S. G. Leonardi, G. Neri, S. Petralia, S. Conoci, F. Priolo and S. Mirabella, Sens. Actuators, B, 2020, 305, 127481. 
20 T. P. Mokoena, H. C. Swart and D. E. Motaung, J. Alloys Compd., 2019, 805, 267-294.

21 X. H. Xia, J. P. Tua, J. Zhang, X. L. Wang, W. K. Zhang and H. Huang, Sol. Energy Mater. Sol. Cells, 2008, 92(6), 628-633.

22 M. Urso, G. Torrisi, S. Boninelli, C. Bongiorno, F. Priolo and S. Mirabella, Sci. Rep., 2019, 9, 7736.

23 H. Lai, Q. Wu, J. Zhao, L. Shang, H. Li, R. Che, Z. Lyu, J. Xiong, L. Yang, X. Wanga and Z. Hu, Energy Environ. Sci., 2016, 9(6), 2053-2060.

24 J. Zheng, W. Zhou, T. Liu, S. Liu, C. Wang and L. Guo, Nanoscale, 2017, 9(13), 4409-4418.

25 M. Schalenbach, F. D. Speck, M. Ledendecker, O. Kasian, D. Goehl, A. M. Mingers, B. Breitbach, H. Springer, S. Cherevko and K. J. J. Mayrhofer, Electrochim. Acta, 2018, 259, 1154-1161.

26 T. Wang, R. Jin, X. Wu, J. Zheng, X. Li and K. Ostrikov, J. Mater. Chem. A, 2018, 6(19), 9228-9235.

27 P. Jiang, Q. Liu and X. Sun, Nanoscale, 2014, 6(22), 13440-13445.

28 G. B. Darband, M. Aliofkhazraei, S. Hyun, A. S. Rouhaghdam and S. Shanmugam, Nanoscale, 2019, 11(35), 16621-16634.

29 X. Meng, J. Han, L. Lu, G. Qiu, Z. L. Wang and C. Sun, Small, 2019, 15(41), 1902551.

30 M. K. Bates, Q. Jia, H. Doan, W. Liang and S. Mukerjee, ACS Catal., 2016, 6(1), 155-161.

31 G. Huang, R. Fan, X. Zhou, Z. Xu, W. Zhou, W. Dong and M. Shen, Chem. Commun., 2019, 55(3), 377-380.

32 I. Roger and M. D. Symes, J. Am. Chem. Soc., 2015, 137(43), 13980-13988.

33 L. Trotochaud, S. L. Young, J. K. Ranney and S. W. Boettcher, J. Am. Chem. Soc., 2014, 136(18), 6744-6753.

34 COMSOL Multiphysics ${ }^{\circledR}$ v. 5.3. www.comsol.com. COMSOL $\mathrm{AB}$, Stockholm, Sweden.

35 R. J. Gilliam, J. W. Graydon, D. W. Kirk and S. J. Thorpe, Int. J. Hydrogen Energy, 2007, 32(3), 359-364.

36 A. Motori and F. Sandrolini, J. Power Sources, 1994, 48(3), 361-370.

37 https://fityk.nieto.pl.

38 L. Geerts, S. Cosentino, T.-W. Liao, A. Yadav, P.-C. Lin, V. S. Zharinov, K.-J. Hu, A. Longo, L. M. C. Pereira, D. Grandjean, J. Rongé, P. Lievens and J. A. Martens, Catal. Today, 2019, 334, 59-67.

39 M. B. Stevens, L. J. Enman, A. S. Batchellor, M. R. Cosby, A. E. Vise, C. D. M. Trang and S. W. Boettcher, Chem. Mater., 2017, 29(1), 120-140.
40 E. Arciga-Duran, Y. Meas, J. J. Perez-Bueno, J. C. Ballesteros and G. Trejo, Electrochim. Acta, 2018, 268, 49-58.

41 V. C. Hoang, K. N. Dinh and V. G. Gomes, Carbon, 2020, 157, 515-524.

42 O. D. Morales, D. F. Suspedra and M. T. M. Koper, Chem. Sci., 2016, 7(4), 2639-2645.

43 Z. Xue, X. Zhang, J. Qin and R. Liu, J. Mater. Chem. A, 2019, 7(40), 23091-23097.

44 P. Oliva, J. Leonardi, J. F. Laurent, C. Delmas, J. J. Braconnier, M. Figlarz and A. D. Guibert, J. Power Sources, 1982, 8, 229-255.

45 D. G. Evans and R. C. Slade, Layered double hydroxides, Springer, 2006, pp. 1-87.

46 B. Wang, C. Tang, H.-F. Wang, X. Chen, R. Cao and Q. Zhang, Adv. Mater., 2019, 31(4), 1805658.

47 T. Shinagawa, A. T. Garcia-Esparza and K. Takanabe, Sci. Rep., 2015, 5, 13801.

48 S. Trasatti, Electrochim. Acta, 1991, 36(2), 225-241.

49 V. D. Silva, T. A. Simones, J. P. F. Grilo, E. S. Medeiros and D. A. Macedo, J. Mater. Sci., 2020, 55(15), 6648-6659.

50 M. Gao, W. Sheng, Z. Zhuang, Q. Fang, S. Gu, J. Jiang and Y. Yan, J. Am. Chem. Soc., 2014, 136(19), 7077-7084.

51 Y. Zhao, X. Jia, G. Chen, L. Shang, G. I. N. Waterhouse, L.-Z. Wu, C.-H. Tung, D. O'Hare and T. Zhang, J. Am. Chem. Soc., 2016, 138(20), 6517-6524.

52 P. T. Babar, A. C. Lokhande, M. G. Gang, B. S. Pawar, S. M. Pawar and J. H. Kim, J. Ind. Eng. Chem., 2018, 60, 493-497.

53 A. C. Pebley, E. Decolvenaere, T. M. Pollock and M. J. Gordon, Nanoscale, 2017, 9(39), 15070-15082.

54 X. Zhou, Z. Xia, Z. Zhang, Y. Ma and Y. Qu, J. Mater. Chem. A, 2014, 2(30), 11799-11806.

55 F. E. S. Oztuna, T. Beyazay and U. Unal, J. Phys. Chem. C, 2019, 123(46), 28131-28141.

56 L. Tong, W. Wu, K. Kuepper, A. Scheurer and K. Meyer, ChemSusChem, 2018, 11(16), 2752-2757.

57 N. Cheng, Q. Liu, J. Tian, X. Sun, Y. He, S. Zhai and A. M. Asiri, Int. J. Hydrogen Energy, 2015, 40(32), 9866-9871.

58 W. Yuan, C. Li, M. Zhao, J. Zhang, C. M. Li and S. P. Jiang, Electrochim. Acta, 2020, 342, 136118.

59 A. Scandurra, A. Porto, L. Mameli, O. Viscuso, V. Del Bo and S. Pignataro, Surf. Interface Anal., 1994, 22(1-12), 353-357.

60 M. C. Biesinger, B. P. Payne, L. W. M. Lau, A. Gerson and R. St. C. Smart, Surf. Interface Anal., 2009, 41(4), 324-332.

61 A. P. Grosvenor, M. C. Biesinger, R. St. C. Smart and N. S. McIntyre, Surf. Sci., 2006, 600(9), 1771-1779. 